\title{
Analisisis Kinerja Sprinkler Mini Meganet 24 D Netafim Terhadap Variasi Debit dan Jarak Penempatan Sprinkler
}

\section{Analysis Of Performance Analysis Of The 24 D Netafim Mini Meganet Sprinkler On Variations Of Disbit and Sprinkler Placement Distance}

\author{
I Dewa Gede Jaya Negara*, Ida Bagus Giri Putra, \\ Anid Supriyadi, Made Anggitha Dewi \\ Jurusan Teknik Sipil, Fakultas Teknik, Universitas Mataram \\ *Corresponding Author Email : jayanegara@unram.ac.id
}

Manuscript received: 08-12-2020. Accepted: 27-10-2021

\begin{abstract}
ABSTRAK
Saat ini alat irigasi sprinkler yang efisien dan efektif sangat banyak dipasaran, sehingga perlu ketelitian dalam memilih untuk irigasi. Diantarannya alat Meganet 24D Netafim termasuk jenis alat irigasi tersebut, yang masih perlu pengujian untuk diketahui kinerja. Penelitian ini bertujuan untuk menguji kinerja irigasi sprinkler Meganet 24D Netafim, pada variasi debit aliran dan jarak antara sprinkler, berkaitan dengan keseragaman irigasi $(\mathrm{CU})$ dan radius irigasinya $(\mathrm{Rn})$. Uji ini dilakukan pada lahan sekitar 1 are, pada debit $\mathrm{Q}_{1}=0.42 / \mathrm{dt}, \mathrm{Q}_{2}=0.51 \mathrm{l} / \mathrm{dt}, \mathrm{Q}_{3}=0.52 / \mathrm{dt}, \mathrm{Q}_{4}=0.56$ dan jarak sprinkler ujinya, $\mathrm{r} 1=2.5 \mathrm{~m}, \mathrm{r} 2=3 \mathrm{~m}, \mathrm{r} 3=3.5 \mathrm{~m}$ dan $\mathrm{r} 4=4 \mathrm{~m}$. Hasil analisis data dipresentasikan berbentuk tabel dan grafik serta disimpulkan secara deskriptif. Hasil penelitian menunjukkan bahwa, pada semua variasi $\mathrm{Q}$ dan jarak sprinkler $\mathrm{r} 1, \mathrm{r} 2, \mathrm{r} 3$ diperoleh keseragaman irigasi (CU) diatas $85 \%$ yang tergolong tinggi, sedangkan pada uji $\mathrm{r} 4, \mathrm{Q}_{1}$ dan $\mathrm{Q}_{2}$ diperoleh $\mathrm{CU}$ dibawah $85 \%$ yang termasuk rendah. Semua variasi debit, menunjukkan radius irigasi (R)sekitar $5 \mathrm{~m}$. Jadi pada jarak sprinkler $\mathrm{r} 4$, tidak disarankan dalam aplikasi irigasi.
\end{abstract}

Kata kunci : keseragaman (cu); radius; irigasi; efisiensi

\begin{abstract}
Currently, there are many efficient and effective sprinkler irrigation tools on the market, so it is necessary to be careful in choosing for irrigation. Among them, the Meganet 24D Netafim, including the type of irrigation tool, which still needs testing to know its performance. This study aims to examine the sprinkler irrigation performance of Meganet 24D Netafim, on variations in flow rate and distance between sprinklers, related to irrigation uniformity $(\mathrm{CU})$ and irrigation radius $(\mathrm{Rn})$. This test was carried out on an area of about 1 acre, at a flow rate of Q1 $=0.42 / \mathrm{sec}, \mathrm{Q} 2=0.51 \mathrm{l} / \mathrm{sec}, \mathrm{Q} 3=0.52 / \mathrm{sec}$, $\mathrm{Q} 4=0.56$ and the test sprinkler distance, $\mathrm{r} 1=2,5 \mathrm{~m}, \mathrm{r} 2=3 \mathrm{~m}, \mathrm{r} 3=3.5 \mathrm{~m}$ and $\mathrm{r} 4=4 \mathrm{~m}$. The results of data analysis are presented in the form of tables and graphs and concluded descriptively. The results showed that, in all variations of $\mathrm{Q}$ and sprinkler spacing $\mathrm{r} 1, \mathrm{r} 2, \mathrm{r} 3$ obtained irrigation uniformity $(\mathrm{CU})$ above $85 \%$ which was classified as high, while in the r4, Q1 and Q2 tests, CU was obtained below
\end{abstract}


$85 \%$ which was considered low. All discharge variations, showing irrigation radius $(\mathrm{R})$ about $5 \mathrm{~m}$. So at $\mathrm{r} 4$ sprinkler spacing, it is not recommended in irrigation applications.

Keywords : uniformity (cu); irrigation; radius; efficiency

\section{PENDAHULUAN}

Pertumbuhan penduduk dari tahun ke tahun semakin membuat jumlah penduduk berkembang sehingga kebutuhan akan terus semakin meningkat. Perkembangan wilayah yang semakin, menuntut permintaan akan pembangunan diberbagai sector yang semakin bertamahnya pembangunan perumahan baru, seperti perkantoran dan berbagai fasilitas umum lainnya yang memaksa lahan pertanian berubah menjadi fungsi lain. Keterbatasan luas lahan pertanian, menuntut produktif lahan yang lebih tinggi dan oleh sebab itu teknologi irigasi juga harus mendukung hal tersebut.

Saat ini telah banyak alat untuk irigasi dipasaran, yang dapat dimanfaatkan untuk membantu irigasi dilahan perkotaan seperti halnya sprinkler yang kecil, disamping harganya murah dan cara operasionalnya sederhana. Oleh karena itu pemaanfaatan irigasi tersebut akan bisa efisien jika system irigasi sprinkler dapat dirancang dengan tepat, penggunaan yang teratur dan sesuai dengan jumlah kebutuhan serta waktu pemberian air (Hansen et al., 1992). Seperti halnya jenis sprinkler mini tipe Meganet 24 D Netafim karena ukurannya kecil, terbuat dari bahan anti UV tahan terhadap perubahan kondisi lingkungan dan bahan-bahan kimia yg digunakan dalam pertanian, mungkin bisa disiapkan untuk irigasi pertanian pada lahan perkotaan yang terbatas. Sprinkler Mini Meganet 24D Netafim dibandingkan dengan sprinkler yang lain, ukurannya kecil sehingga mudah dibawa dan mudah pemasangannya dan juga ekonomis.

Berdasarkan hal di atas, maka perlu dilakukanlah uji tentang kinerja irigasi sprinkler mini Meganet 24 D Netafim, agar dapat digunakan dalam perancangan jaringan irigasi yang efektif pada luas lahan yang terbatas. Uji perlu dilakukan terhadap kemampuan pembasahan irigasinya baik radius irigasinya maupun keseragamannya, agar luas areal yang mampu diberi irigasi dengan ketersediaan air tertentu. Dengan diketahuinya ke dua kinerja tersebut pada variasi debit tertentu, maka akan dapat dilakukan uji lebih lanjut dan diaplikasi pada usahatani jenis tanaman tertentu. Akan tetetapi sebelum dapat dilakukan hal tersebut, lebih lanjut perlu diketahui besar koefisien keseragaman irigasi sprinkler yang diperoleh pada jarak antar sprinkler tertentu dan pada variasi debit aliran tertentu. Bagaimana pengaruh jarak sprinkler terhadap variasi debitnya, apakah semua memberi indikasi yang sama atau seragam. Pada jarak antara sprinkler berapa diperoleh keseragaman yang baik untuk digunakan dalam irigasi tanaman. Dan untuk memperoleh jawaban tersebut perlu dilakukan penelitian ini pada luas lahan dan debit aliran yang terbatas, agar evaluasi dan perbaikan untuk memperoleh hasil uji yang diharapkan dapat dilakukan lebih spesifik. Penelitian lapangan dilakukan di daerah Rembiga Kota Mataram pada lahan uji sekitar $100 \mathrm{~m}^{2}$ (1 are), dan sumber air dari pompa shimizu PS 121 BIT dengan daya $125 \mathrm{~W}$ dan kapasitas $31 \mathrm{l} / \mathrm{menit}$. Dengan menggunakan debit dari pompa, maka diharapkan debit dapat divariasi lebih beragam, sehingga kinerja sprinkler dapat diketahui lebih spesifik dan hasil kinerja yang 
lebih rinci. Berdasarkan hasil uji tersebut maka penggunaan sprinkler ini bisa dibatasi dalam penggunaan di usahatani, sehingga penggunaannya lebih sesuai.

Menurut Nopianti, (2015), dari hasil studinya tentang analisis pengaruh pemberian irigasi sprinkler mini dan penggenangan terhadap kedalaman resapan dan luas basahan pada lahan kering Pringgabaya. Menunjukkan bahwa semakin lama irigasi sprinkler mini digunakan maka semakin dalam capaian resapan air irigasi yang dihasilkan, dan semakin besar tekanan air yang diberikan maka semakin besar luas radius basahan yang dihasilkan. Sedangkan irigasi penggenangan, semakin besar debit yang digunakan maka semakin cepat terjadinya proses pembasahan lahan. Untuk irigasi 60 menit, hanya mampu bertahan dalam tanah selama 5 hari. Sedangkan menurut Jaya Negara, IDG dkk (2015) yang meneliti karakteristik kinerja irigasi sprinkler Mini tiga nozzle di lahan kering Pringgabaya Utara Kabupaten Lombok Timur, menunjukkan hasil bahwa keseragaman $(\mathrm{Cu})$ irigasi sprinkler mini besarnya rata - rata diatas $70 \%$, tergolong baik dengan kedalaman capaian irigasi sekitar $0.3 \mathrm{~cm}-7$ $\mathrm{cm}$. Besar debit sprinkler mini rata- rata $0.023 \mathrm{~m}^{3} / \mathrm{dt}$ dengan radius capaian irigasi $(\mathrm{rs})=2.6 \mathrm{~m}$.

Dalam sistem irigasi biasa, 50\% air yang digunakan untuk irigasi, digunakan untuk tanaman, dan sisanya hanya terbuang percuma. Dengan menggunakan sistem irigasi sprinkler dapat menghemat 50\% air dibandingkan dengan metode irigasi. Air merupakan faktor kunci dalam meningkatkan kualitas dari tanaman. Irigasi merupakan cara yang bisa digunakan untuk meningkatkan kualitas dari tanaman. Salah satu cara irigasi modern adalah dengan menggunakan sistem irigasi sprinkle. Cara ini sangat populer di seluruh negara maju di dunia.

Sistem irigasi sprinkle ini pada dasarnya menggunakan air yang bertekanan dan keluar melalu perangkat yang disebut sebagai penyiram (sprinkler). Penyiram (sprinkler) biasanya terletak pada pipa yang disebut lateral. Air disemprotkan ke udara dan kemudian jatuh masuk ke dalam tanah, menyirami tanaman yang ada di sekitarnya.

Sistem irigasi sprinkler menggunakan sistem penyemprotan air seperti curah hujan alami. Tekanan air disalurkan kemudian dikeluarkan melalui nozzle yang kemudian memecahkan air sehingga keluar seperti titik-titik air hujan. Tekanan air berasal dari pompa yang mendorong air melalui pipa kemudian keluar melalui nozzle. Nozzle selain berfungsi sebagai pemecah air, juga dapat digunakan untuk mengatur tekanan jarak dan banyak sedikitnya air yang keluar.

Komponen dalam sistem irigasi sprinkler ini meliputi sumber air, baik dari sumber air yang terbuka (misalnya, sungai, kolam, danau, waduk, dll) maupun yang berasal dari tempat tampungan air (misalnya tandon air, ground tank, sumur, dll). Unit untuk mendorong air sehingga menghasilkan air yang bertekanan untuk kemudian disalurkan melalui pipa dan keluar melalui nozzle (misalnya pompa).

Umumnya sistem irigasi sprinkler ini sering digunakan pada tanah normal, maupun tanah dangkal. Cocok juga untuk medan yang berpasir, medan yang bergelombang, hingga banyak diadopsi untuk pengairan di daerah perbukitan. Untuk penanaman ladang cocok untuk semua jenis ladang / kebun. Untuk perkebunan seperti kebun sayuran, bawang merah, pembibitan di area terbuka dapat mengadopsi sistem irigasi sprinkler ini.

Keunggulan irigasi sprinkler antara lain efisiensi pemakaian air cukup tinggi,dapat digunakan untuk lahan dengan topografi bergelombang dan kedalaman tanah (solum) yang 
dangkal, tanpa diperlukan perataan lahan (land grading), cocok untuk tanah berpasir yang laju infiltrasi cukup tinggi, aliran permukaan dapat dihindari sehingga memperkecil kemungkinan terjadinya erosi, pemupukan terlarut, herbisida dan fungisida dapat dilakukan bersama-sama dengan air irigasi,biaya tenaga kerja untuk operasi biasanya lebih kecil daripada irigasi permukaan, dengan tidak diperlukannya saluran terbuka, maka sedikit lahan yang tidakdapat ditanami, tidak mengganggu operasi alat dan mesin pertanian (Kartasapoetra, et al, 1990).

Selain itu dalam aplikasi irigasi juga sangat tergantung pada kondisi infiltrasi lahan seperti lhan kering, karena durasi irigasi ujga sangat tergantung pada kemampuan lahan menyerap dan menyimpan air dari permukaan (Negara IDGJ et.al.,2021), telah mengkaji karakteristik infiltrasi lahan dibeberapa lokasi lahan kering Lombok utara dimana hasilnya menunjukkan bahwa laju infiltrasi rata-rata di Desa Anyar pada 4 lokasi dengan tanah liat berpasir, klisifikasi laju infiltrasinya 2 lokasi termasuk sangat cepat dan 2 lokasi lagi termasuk cepat dan agak cepat. Sedangkan pada Desa Sukadana laju infiltrasi pada kondisi tanah pasir ber tanah liat, klasifikasi laju infiltrasi 2 lokasi termasuk sangat cepat dan 2 lokasi lagi termasuk agak cepat. Berdasarkan hasil uji infiltrasi tersebut maka untuk infiltrasi sangat cepat dan cepat berpotensi diterapkan irigasi pancar seperti sprinkler atau perforasi dan untuk infiltrasi agakcepat perbotensi diterapkan irigasi sistem tetes dan leb terbatas.

Jadi kondisi tanah perlu menjadi pertimbangan dalam aplikasi sistem irigasi 24D Netafim, karena sangat mungkin diterapkan pada tanah lahan kering dengan sumber air yang terbatas.

\section{Koefisien Keseragaman}

Untuk menghitung koefisien keseragaman persamaan Critiansen (1942) dapat dijadikan acuan dalam perencanaan :

$$
C u=100\left(1-\frac{\sum^{i=n}|x i-x|}{\gamma_{n}}\right)
$$

dengan : $\mathrm{Cu}=$ koefisien keseragaman (Uniformity of application), $\mathrm{xi}=$ hasil tampungan $(\mathrm{ml})$, $\mathrm{x}=$ rata-rata hasil tampungan, $\mathrm{n}=$ jumlah titik observasi (number of observation)

\section{Debit Alirn}

Untuk perhitungan debit dapat digunakan persamaan berikut : $\mathrm{Q}=\mathrm{V} / \mathrm{t}$

dengan: $\mathrm{Q}=$ debit aliran $\left(\mathrm{m}^{3} / \mathrm{det}\right) ; \mathrm{V}=$ volume tampungan wadah $\left(\mathrm{m}^{3}\right) ; \mathrm{t}=$ lama waktu untuk memenuhi volume wadah yang digunakan (detik), (Triatmojo,2012)

\section{Kecepatan Aliran}

Dalam penelitian ini persamaan yang dilakukan untuk mengetahui besarnya kecepatan aliran air yang terjadi dalam pipa yaitu persamaan kontonuitas sebagai berukut :

$$
\mathrm{V}=\mathrm{Q} / \mathrm{A}
$$

dengan : V= kecepatan aliran (m/dt), $Q=$ debit aliran $\left(\mathrm{m}^{3} / \mathrm{dt}\right),($ Triatmojo, 2013) 


\section{BAHAN DAN METODE}

\section{Bahan Penelitian dan Peralatan Pendukung.}

Bahan yang digunakan dalam penelitian terdiri dari, sprinkler 24 D Netafim, air dari sungai terdekat, pipa PVC $3 / 4$ inch, pipa pve $1 / 2$ inch dan asesoris pipa. Sedang untuk mendapatkan tekanan dignakan pompa air Shimizu PS 121 BIT dengan daya hisap yang maksimal dengan voltage 220/50, daya dorong max. $33 \mathrm{~m}$ dan panjang pipa hisap $9 \mathrm{~m}$. Spesifikasi pompa air ini terdiri dari Daya Output Motor : $125 \mathrm{~W}$, Daya Input Motor : $0.35 \mathrm{Kw}$, Pipa hisap : $1 / 2$ inch, Pipa dorong : 1/2 inch, dengan sprinkler dan pompa seperti pada gambar berikut.

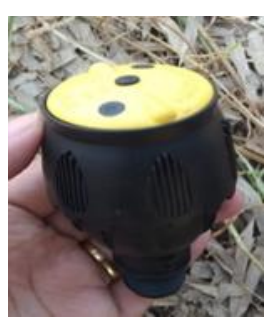

Gambar 1 Meganet 24 D Netafim

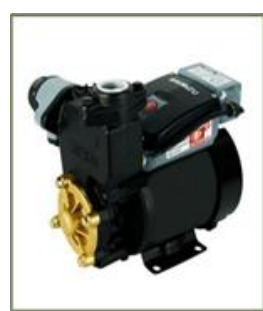

Gambar 2. Pompa air shimizu PS 121 BIT

Peralatan pendukung yang digunakan dalam penelitian ini terdiri dari alat penelitian dan alat bantu seperti gergaji pipa, meteran, mangkuk plastic, yang digunakan untuk menampung distribusi irigasi, alat tulis, kamera dan meteran air untuk mengukur debit aliran yang digunakan dalam uji. Spesifikasi Pompa Air.

\section{Rancangan Sistem Jaringan sprinkler}

Rancangan sistem jaringan irigasi sprinkler, terdiri dari jaringan pipa dan penempatan sprinkler dengan jarak yang akan divariasi pada petak lahan 1 are. Gambar jaringan dan skema penempatan sprinkler dapat dilihat pada Gambar 2.

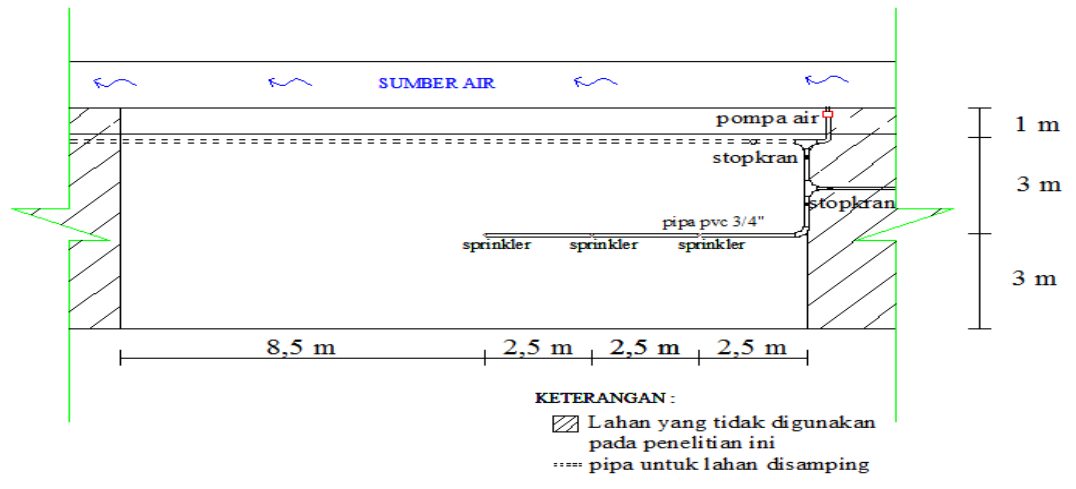

Gambar 2.Skema jaringan pada jarak sprinkler dengan $\mathrm{R} 1=2.5 \mathrm{~m}$

Berdasarkan gambaran jaringan di atas, maka pengujian akan menggunakan 4 jarak sprinkler akan divariasi dan pada gambar di atas untuk jarak R1.

\section{Pelaksanaan Pengujian sprinkler}

Secara garis besar langkah - langkah pelaksanaan penelitian uji sprinkler ini dilakukan sebagai berikut. 
1. Pengujian awal, kegiatan ini terdiri dari pengujian jaringan perpipaan yang tujuannya untuk mengetahui kondisi aliran dalam jaringan perpipaan dan untuk menjamin alirannya baik. Kemudian dilakukan pengujian debit aliran, pengujian ini bertujuan untuk memperoleh besaran variasi debit yang dapat digunakan untuk pengujian irigasi sprinkler. Pengujian debit pompa ini dilakukan 5 kali uji pada 4 kali variasi sudut bukaan stopkran yaitu $30^{\circ}, 50^{\circ}, 70^{\circ}$ dan $90^{\circ}$, dengan data uji debit hasil pengujian yang diperoleh ditunjukkan pada Tabel1.

Tabel 1. Hasil Pengujian Debit Pompa

\begin{tabular}{cccccccccc}
\hline $\begin{array}{c}\text { Sudut } \\
\text { bukaan } \\
\begin{array}{c}\text { Stopkran } \\
\left({ }^{\circ}\right)\end{array}\end{array}$ & $\begin{array}{c}\text { Volume } \\
\text { Ember } \\
\text { (liter) }\end{array}$ & t1 & t2 & t3 & t4 & t5 & $\begin{array}{c}\text { Waktu } \\
\text { Rata-rata } \\
\text { (detik) }\end{array}$ & $\begin{array}{c}\text { Debit } \\
\text { Pompa } \\
\text { (liter/detik) }\end{array}$ \\
\hline 30 & 10.45 & 26 & 25 & 24 & 24 & 25 & 24.8 & 0.42 \\
50 & 10.45 & 21.0 & 21.0 & 20.0 & 20.0 & 21.0 & 20.6 & 0.51 \\
70 & 10.45 & 20.0 & 21.0 & 19.0 & 21.0 & 20.0 & 20.2 & 0.52 \\
90 & 10.45 & 18,0 & 18.0 & 19,0 & 20.0 & 19.0 & 18.8 & 0.56 \\
\hline
\end{tabular}

Sumber : Hasil Perhitungan

2. Tahap pelaksanaan penelitian terdiri dari pengujian keseragaman irigasi pada variasi debit pompa, pengujian radius pancaran irigasi sprinkler pada variasi debit aliran aprinkler dan pengujian keseragaman pada variasi jarak sprinkler $\left(R_{1}=2.5 \mathrm{~m}, \mathrm{R}_{2}=3 \mathrm{~m}\right.$, $\mathrm{R}_{3}=3.5 \mathrm{~m}$ dan $\mathrm{R}_{4}=4 \mathrm{~m}$. Semua data yang diperoleh dari pengujian yang menghasilkan data keseragaman akibat variasi jarak dan variasi debit, kemudian dikumpulkan dan diperiksa serta disiapkan untuk analisis data uji.

3. Analisis data. Dalam tahap ini dilakukan analisis variasi debit pompa terhadap radius pancaran sprinkler, analisis debit pompa terhadap keseragaman irigasi yang dicapai dan hubungan keseragaman irigasi dengan radius pancaran irigasi sprinkler. Pada tahap analisis juga dilakukan pembahasan hasil semua data yang dipresentasikan dalam bentuk grafik dan tabel dan disimpulkan secara deskriptif.

\section{Analisis Debit Pompa}

\section{HASIL DAN PEMBAHASAN}

Berdasarkan perhitungan pada Tabel 1, debit pompa pada bukaan stopkran $30^{\circ}$ diperoleh $\mathrm{Qp}=0.421 /$ detik, bukaan stopkran $50^{\circ}$ diperoleh $\mathrm{Qp}=0.51 \mathrm{1} /$ detik, bukaan stopkran $70^{\circ}$ diperoleh Qp $=0.52$ 1/detik, dan bukaan stopkran $90^{\circ}$ (bukaan stopkran penuh) diperoleh Qp $=0.56 \mathrm{l} /$ detik. Variasi debit pompa ini yang akan digunakan untuk melakukan pengujian variasi debit terhadap kinerja sprinkler. Jadi berdasarkan hasil uji tersebut, ternyata pompa hanya mampu memberikan debit terendah hanya sekitar $0.421 / \mathrm{dt}$ dan debit maksimum 0.56 1/dt sebagai pembatas dari pompa pada jaringan sprinkler ini. Oleh karena itu maka debit ini merupakan faktor pembatas uji sistem irigasi ini, sehingga dalam penggunaan dalam pengairan tanaman dapat dilakukan lebih cermat. 


\section{Radius Pancaran Irigasi Sprinkler}

Pengaruh debit aliran terhadap radius pancaran irigasi sprinkler meganet 24 D Netafim ini merupakan faktor penting yang perlu dicermati dalam irigasi. Besarnya debit, bukan satusatunya yang menentukan bahwa irigasi dapat dilakukan dengan alat sprinkler ini dan akan tetapi yang perlu diperhatikan adalah dengan besaran debit tersebut berapa radius irigasi yang diperoleh untuk pembasahan lahan dan bagaimana keseragaman yang baik dapat diberikan. Oleh karena itu untuk mendapatkan ukuran kinerja yang baik sistem irigasi ini maka ke dua pertimbangan tersebut dapat digunakan sebagai syarat. Data hasil uji variasi debit dan variasi jarak sprinkler terhadad radius irigasi yang dihasilkan dapat dilihat pada Tabel 2.

Tabel 2. Radius Pancaran Irigasi pada variasi debit dan Jarak Sprinkler

\begin{tabular}{ccccc}
\hline $\begin{array}{c}\text { Debit Pompa } \\
(\mathrm{Qp})(1 / \mathrm{dt})\end{array}$ & $\begin{array}{c}\text { Jarak sprinkler } \\
\left(\mathrm{R}_{1}\right) 2.5 \mathrm{~m}\end{array}$ & $\begin{array}{c}\text { Jarak prinkler } \\
\left(\mathrm{R}_{2}\right) 3 \mathrm{~m}\end{array}$ & $\begin{array}{c}\text { Jarak sprinkler } \\
\left(\mathrm{R}_{3}\right) 3.5 \mathrm{~m}\end{array}$ & $\begin{array}{c}\text { Jarak sprinkler } \\
\left(\mathrm{R}_{4}\right) 4 \mathrm{~m}\end{array}$ \\
\hline 0.42 & 4.90 & 4.90 & 4.89 & 4.87 \\
0.51 & 4.99 & 5.00 & 5.00 & 5.00 \\
0.52 & 5.11 & 5.11 & 5.12 & 5.10 \\
0.56 & 5.30 & 5.29 & 5.26 & 5.17 \\
\hline
\end{tabular}

Sumber: Hasil analisis

Berdasarkan hasil uji pada tabel 2 diatas, diketahui bahwa pada setiap variasi jarak sprinkler menunjukkan hasil radius pancaran yang berbeda. Dimana pada jarak sprinkler $\mathrm{R}_{1}$ sampai dengan $\mathrm{R}_{4}$, semuanya menunjukkan radius pancaran irigasi sprinkler yang dihasilkan semakin besar jika debit yang diberikan pada sistem irigasi semakin besar. Jadi secara umum alat ini mampu memberikan radius irigasi sekitar 5 meter dan sesuai dengan spesifikasi alat tersebut. Jika dibandingkan dengan sprinkler tiga nozzle pada uji (Negara IDGJ, et al., 2015), maka hasil uji sprinkler Meganet 24D Netafim memiliki jangkauan irigasi jauh lebih panjang sehingga luas areal irigasinyapun lebih luas.

\section{Analisis Keseragaman Irigasi $(C U)$}

Hasil analisis keseragaman irigasi sprinkler yang diperoleh dari hasil pengujian dapat dilihat pada Tabel 3. Berdasarkan hasil analisis tersebut diketahui bahwa keseragaman yang dihasilkan oleh variasi debit sangat beragam dan rata-rata pada debit di atas Q1 diperoleh keseragaman di atas $85 \%$, khususnya pada jarak antar sprinkler $\mathrm{R}_{1}$ sampai $\mathrm{R}_{3}$, sedangkan pada jarak antar sprinkler $\mathrm{R}_{4}$ pada debit uji Q1 diperoleh keseragaman di bawah $85 \%$ bahkan dibawah $80 \%$. Hal ini menunjukkan bahwa pada $\mathrm{Q} 1$ dan jarak sprinkler $\mathrm{R}_{4}$, debit sudah tidak cukup memberikan keseragaman yang baik pada pemberian irigasi. Jadi kondisi ini memberikan informasi bahwa untuk menggunakan jarak antar sprinkler $\mathrm{R}_{4}$ dan mungkin dengan jarak antar sprinkler yang lebih besar lagi, maka diperlukan debit pompa yang lebih besar. 
Tabel 3. Nilai Keseragaman Irigasi pada Variasi R dan Q

\begin{tabular}{ccccc}
\hline $\begin{array}{c}\text { Jarak, R } \\
(\mathrm{M})\end{array}$ & $\begin{array}{c}\text { Koefisien CU }(\%) \\
\text { pada Q1 }\end{array}$ & $\begin{array}{c}\text { Koefisien CU } \\
(\%) \text { pada Q2 }\end{array}$ & $\begin{array}{c}\text { Koefisien CU (\%) } \\
\text { pada Q3 }\end{array}$ & $\begin{array}{c}\text { Koefisien CU } \\
(\%) \text { Pada Q4 }\end{array}$ \\
\hline 2.5 & 85.35 & 85.72 & 86.00 & 86.29 \\
3.0 & 85.00 & 85.14 & 85.59 & 86.11 \\
3.5 & 85.09 & 85.15 & 85.24 & 85.58 \\
4.0 & 70.06 & 85.09 & 85.06 & 85.23 \\
\hline
\end{tabular}

sumber: hasil analisis

Untuk lebih jelasnya grafik pada bahasan berikut akan memberikan rincian lebih detail tentang pengarih variasi debit dan jarak antar sprinkler pada keseragaman irigasi yang dihasilkan. Hasil uji ini termasuk sangat baik

ahwa keseragaman $(\mathrm{Cu})$ irigasi sprinkler mini besarnya rata - rata diatas $70 \%$, tergolong baik dengan kedalaman capaian irigasi sekitar $0.3 \mathrm{~cm}-7 \mathrm{~cm}$. Besar debit sprinkler mini ratarata $0.023 \mathrm{~m}^{3} / \mathrm{dt}$ dengan radius capaian irigasi $(\mathrm{rs})=2.6 \mathrm{~m}$.

\section{Pengaruh jarak antar sprinkler terhadap keseragaman}

Hasil analisis uji variasi jarak antar sprinkler dan variasi debit terhadap keseragaman irigasi (CU) dapat dilihat pada empat grafik pada bahasan berikut. Untuk variasi jarak antar sprinkler $2.5 \mathrm{~m}$ dan $3 \mathrm{~m}$, grafik gasil analisisnya ditunjukkan pada Gambar 4. Berdasarkan grafik tersebut diketahui bahwa pada jarak antar sprinkler $2.5 \mathrm{~m}$ diperoleh keseragaman yang semakin meningkat pada pemberian debit uji yang semakin besar, dan pada uji Q1 diperoleh Cu sebesar 85.34\% dan pada Q4 diperoleh CU sebesar 86.29\%.
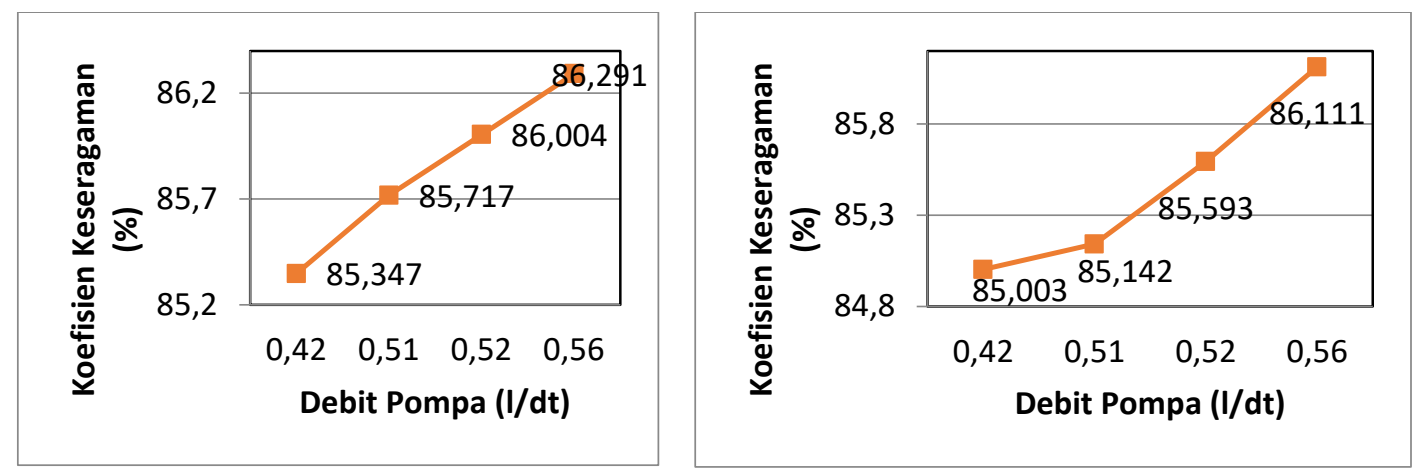

Gambar 4. Grafik Hubungan Keseragaman irigasi pada jarak antar sprinkler $2.5 \mathrm{~m}$ dan $3 \mathrm{~m}$

Untuk jarak sprinkler 3m juga diperoleh nilai CU yang besar dimana nilainya dari $85 \%$ sampai dengan $86.29 \%$. Berdasarkan grafik di atas, keduanya memberikan kecederungan nilai CU yang semakin meningkat walaupun peninmgkatan nilai CUnya yang berbeda, Ketika deberika debit aliran yang semakin besar dari Q1 sampai dengan Q4.

Untuk variasi jarak antar sprinkler $3.5 \mathrm{~m}$ dan $4 \mathrm{~m}$, grafik gasil analisisnya ditunjukkan pada Gambar 5. Berdasarkan grafik tersebut diketahui bahwa pada jarak antar sprinkler $3.5 \mathrm{~m}$ diperoleh keseragaman yang juga semakin meningkat pada pemberian debit uji yang semakin besar, dan pada debit uji Q1 diperoleh nilai Cu sebesar 85.09\% dan pada Q4 diperoleh CU sebesar $85.57 \%$. 

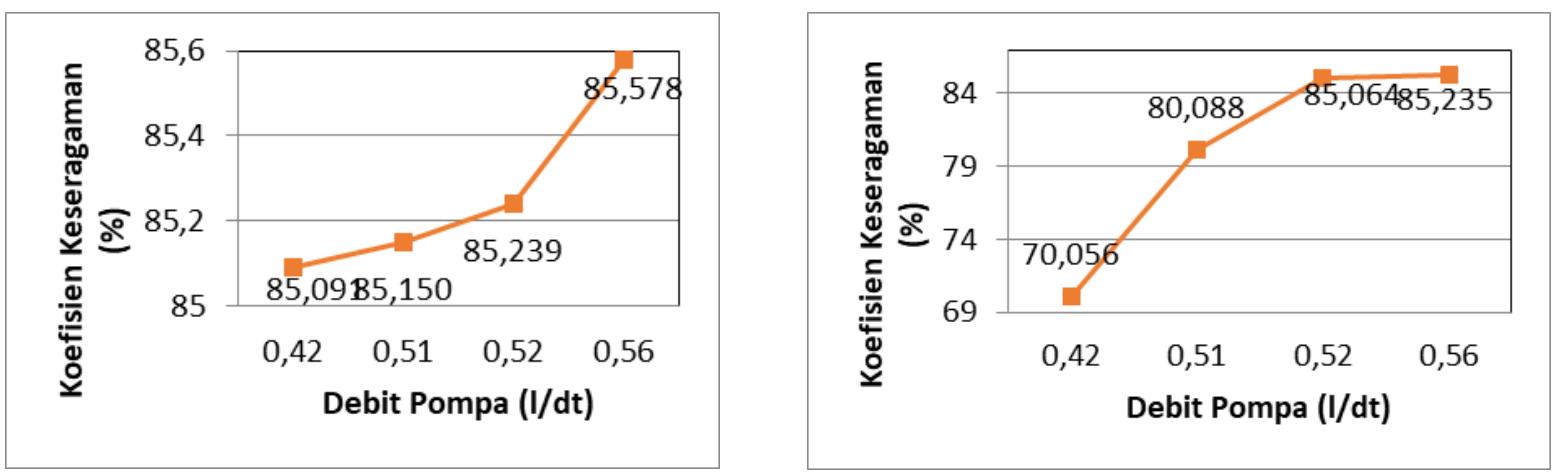

Gambar 5. Grafik Hubungan Keseragaman irigasi pada jarak antar sprinkler 3.5m dan $4 \mathrm{~m}$

Berdasarkan grafik Gambar 5 di atas diketahui bahwa pada jarak antar sprinkler $4 \mathrm{~m}$ diperoleh keseragaman yang juga semakin meningkat pada pemberian debit uji yang semakin besar, namun besar CU ada masih dibawah $80 \%$ yaitu pada Q1. Sedangkan pada uji dengan Q2 sampai Q4 diperoleh nilai CU 80\% sampai 85.23\%. Berdasarkan hasil ini menunjukkan bahwa pada jarak antar sprinkler $4 \mathrm{~m}$, keseragaman yang diperoleh termasuk rendah dan tidak layak digunakan pada debit minimum Q1. Selain itu pada Gambar 6 juga dapat dilihat grafik gabungan hasil uji tersebut di atas.

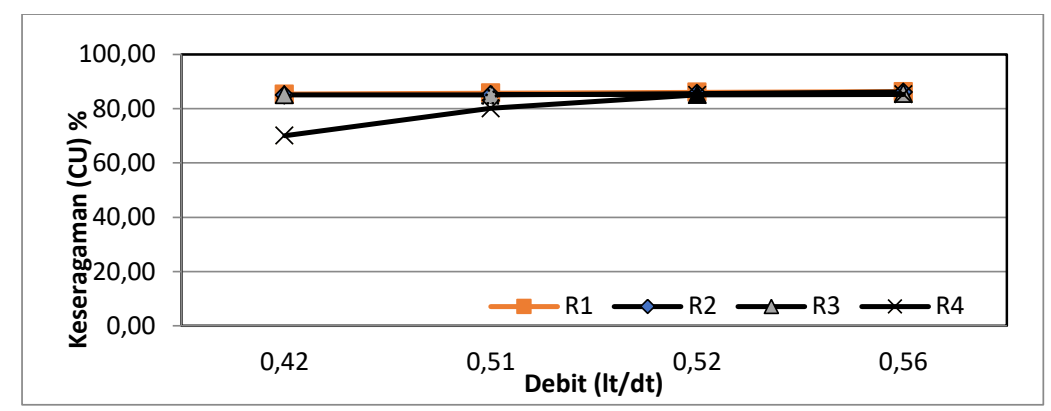

Gambar 6. Grafik Hubungan Keseragaman irigasi, jarak antar sprinkler dan variasi debit

Berdasarkan grafik pada Gambar 6 dapat dilihat lebih jelah bahwa, pada jarak antar sprinkler $\mathrm{R}_{4}$ memang manghasilkan keseragaman yang paling rendah sehingga tidak layak digunakan untuk irigasi jika debit yang digunakan Q1. Sedangkan pada uji dengan debit Q2 sampai dengan Q4, hasil keseragaman CU sebesar 80\% cukup baik jika digunakan untuk irigasi.

Jadi berdasarkan grafik diatas bahwa untuk keseragaman CU yang diperoleh sebesar $70 \%$, hasil penelitian pada $\mathrm{R}_{4}$, ini hampir mirip dengan kinerja sprinkler tiga nozzle yang diuji di Pringgabaya oleh Negara IDGJ, et al.,(2015). Sprinkler tiga nozzle tersebut, digunakan hanya untuk pembahasahan permukaan lahan irigasi untuk mengatasi evaporasi harian saja karena suhu harian kondisi permukaan cukup tinggi maka masih tetap bisa digunakan. Akan tetapi kalau untuk pemberian irigasi tanaman, maka sprinkler tiga nozzle belum dapat digunakan. Jadi oleh karena jika jarak antar sprinkler $\mathrm{R}_{4}$ mungkin dapat digunakan untuk mangatasi kebutuhan air evaporasi harian dengan keunggulan radius irigasinya lebih luas dari pada sprinkler tiga nozzle. 


\section{KESIMPULAN}

Berdasarkan hasil penelitian ini maka dapat disimpukan bahwa, pada semua variasi Q dan jarak sprinkler $\mathrm{R}_{1}, \mathrm{R}_{2}, \mathrm{R}_{3}$ yang diuji diperoleh keseragaman irigasi (CU) di atas $85 \%$ yang tergolong tinggi, sedangkan pada uji dengan jarak antar sprinkler $\mathrm{R}_{4}$ dan $\mathrm{Q}_{1}$ diperoleh $\mathrm{CU}$ dibawah $85 \%$ dan termasuk rendah. Pengujian pada semua variasi debit, menunjukkan radius irigasi sprinkler meganet 24 D Netafim sekitar $5 \mathrm{~m}$. Jadi perancangan sprinkler dengan jarak antar sprinkler $\mathrm{R}_{4}$, tidak disarankan dalam aplikasi irigasi.

\section{Ucapan Terima Kasih}

Ucapan terimaksih kami disampaikan kepada tim pengujian lapangan yang telah memberikan hasilnya untuk dipublikasikan dalam seminar nasional.

\section{DAFTAR PUSTAKA}

Hansen, V. E., O. W. Israelsen, dan G. E. Stringham, 1992. Dasar-Dasar dan Praktek Irigasi. Penerbit: Erlangga, Jakarta,

Jaya Negara, I Dewa Gede. 2015. Karakteristik Kinerja Irigasi Sprinkler Mini Pada Lahan Kering Pringgabaya Utara Kabupaten Lombok Timur, Universitas Mataram,

Kartasapoetra, dan Sutedjo, M.M. 1990 dalam Agastya AA Gde, 2010, Teknologi Pengairan Irigasi, Bina Aksara, Jakarta.

Triatmodjo, B. 2012, Hidraulika I, Yogyakarta,

Triatmodjo, B. 2013, Hidraulika II, Edisi II, Beta Offset, Yogyakarta,

Nopianti 2015, Analisa Pengaruh Pemberian Air Irigasi Sprinkler Mini dan PenggenanganTerhadap Kedalaman Resapan Dan Luas Basahan Pada Lahan KeringPringgabaya, Skripsi FT,Universitas Mataram,

Negara IDGJ, Hanifah L, Saidah H, Anwar S. 2021. Karakteristik Infiltrasi dan Potensi Irigasi di Lahan Kering Kecamatan Bayan Kabupaten Lombok Utara,JurnalSainsTeknologi\&Lingkungan,Vol. 7 No.1, ISSN :2477-0329, e-ISSN : 2477-0310, pp:134-145, Juni 2021 